\title{
DESENVOLVIMENTO SUSTENTÁVEL: GOVERNANÇA E INDICADORES PARA O SETOR PÚBLICO
}

\author{
Gleimíria Batista da Costa* \\ Maray del Carmen S. Rodrigues** \\ Oleides Francisca de Oliveira*** \\ Marcos Cesar dos Santos*****
}

\begin{abstract}
Resumo
Este artigo apresenta reflexões sobre o desenvolvimento sustentável, governança e indicadores de sustentabilidade, especialmente no que concerne ao que vem sendo desenvolvido por meio da gestão pública governamental. O levantamento acerca dos seguintes temas é apresentado: Desenvolvimento sustentável, governança, indicadores de sustentabilidade para o setor público e questões gerais sobre sustentabilidade no Brasil. Trata-se de uma pesquisa bibliográfica de abordagem qualitativa. Os resultados mostram o uso de indicadores de desempenho em análise política no contexto do desenvolvimento sustentável a fim de apoiar gestores públicos e garantir que estes tomem decisões melhores informadas. Muitas organizações internacionais, países e regiões têm apresentado o uso de indicadores, mas poucos têm controlado a sua utilização.
\end{abstract}

Palavras-chave: Desenvolvimento Sustentável. Governança. Indicadores de Sustentabilidade. Sustentabilidade no Brasil.

\footnotetext{
* Doutora em Desenvolvimento Regional pela Universidade de Santa Cruz do Sul/UNISC. Docente do Curso de Ciências Contábeis da Universidade Federal de Rondônia-UNIR. E-mail: gleimiria@unir.br.

** Mestre em Administração do Programa de Pós-Graduação Mestrado em Administração - PPGMAD da Universidade Federal de Rondônia.marayrodrigues@hotmail.com

*** Doutora em Desenvolvimento Regional pela Universidade de Santa Cruz do Sul/UNISC. Docente do Curso de Ciências Contábeis da Universidade Federal de Rondônia-UNIR. E-mail: oleides@yahoo.com.br **** Mestre em Administração. Docente do Curso de Administração da Universidade Federal de Rondônia-UNIR. E-mail: profmarcoscesar@hotmail.com
} 


\section{Introdução}

O documento das Nações Unidas de 1987, chamado "Nosso Futuro Comum", propõe o desenvolvimento sustentável como um processo de mudança, em que a exploração de recursos, os investimentos e o desenvolvimento deveriam estar vinculados às necessidades das gerações atual e futuras. Esse desenvolvimento seria alcançado com a participação de múltiplas perspectivas para compreender adequadamente a complexidade de questões, e para reunir o apoio para implantar iniciativas nesse sentido.

George (2007) entende que o conceito de desenvolvimento sustentável tem evoluído consideravelmente, mas os problemas que se pretendem abordar permanecem sem solução. Tornou-se uma norma amplamente aceita, mas ainda apresenta problemas quanto ao seu entendimento.

Quanto à metodologia, este ensaio caracteriza-se como teórico, com base em pesquisa bibliográfica, documental e de natureza qualitativa. A literatura, basicamente internacional, tem apontado para a importância do uso de indicadores de desempenho em análise política, dentro do contexto de desenvolvimento sustentável, para apoiar gestores públicos e garantir que estes tomem decisões melhores informadas. Entretanto, apesar de muitas organizações internacionais, países e regiões terem apresentado o uso de indicadores, mas poucos têm controlado a sua utilização, o que servirá para apontarmos algumas reflexões sobre o contexto brasileiro.

\section{Governança e sustentabilidade}

A conferência do Rio interpretou o desenvolvimento sustentável como um processo com três dimensões. Já o Plano de Aplicação de Johanesburgo definiu-o como três processos distintos, que se reforçam mutuamente: desenvolvimento econômico, desenvolvimento social e proteção ambiental (GEORGE, 2007).

Quando da elaboração da Agenda21(UNCED,1992),as Nações Unidas chamaram a atenção para o desenvolvimento sustentável das nações, prevendo a harmonização e ampliação de políticas e planos por meio da adoção de uma estratégia para tal desenvolvimento. $\mathrm{O}$ objetivo global não era desenvolver um novo documento estratégico, mas melhorar, ou até mesmo, reestruturar o processo de tomada de decisão, de modo que o exame socioeconômico e as questões 
ambientais fossem totalmente integrados, além de garantir uma ampla participação do público (UNCED, 1992). Nessa última afirmação, já se observa preocupações com a elaboração de formas de gestão e governança e de políticas voltadas ao desenvolvimento sustentável enquanto bem comum.

Governança trata-se de um conceito amplo e com muitas conotações, mas está sempre relacionada às questões de como orientar e de como ser dirigida (OSBORNE E GAEBLER, 1992). Muitas vezes, governança é vista como uma mudança de direção cultural a partir do estilo tradicional, que de acordo com a Jordânia et al. (2003), pode ser interpretada como uma "forma de governar baseado em atividades, realizadas principalmente ou totalmente por organismos estatais, particularmente a nível de Estado-nação"(p. ).

Para Mineur (2007), Governança é geralmente associada a um vasto âmbito dos atores envolvidos numa perspectiva de baixo para cima, em que as fronteiras entre os setores públicos e privados, bem como entre os diferentes níveis administrativos, são menos acentuadas.

Segundo o The Journal of Environment \& Development (2008), a interpretação de Johanesburgo sobre o desenvolvimento sustentável, em relação ao significado do desenvolvimento econômico, é obscura, mas o identifica como uma referência essencial. Concorda-se que a qualidade, e não apenas sua quantidade, do crescimento é um fator significativo para melhorar a qualidade da vida humana (BANCO MUNDIAL, 2000). O crescimento, entretanto, é considerado uma condição necessária para o desenvolvimento, mesmo não sendo suficiente. Muitos eruditos o contestaram. John Stuart Mill (1848/1909) previu um momento quando o crescimento econômico se tornaria ambientalmente insustentável, usando os mesmos termos que foram utilizados nas conferências de Estocolmo e do Rio para descrever o que aconteceria.

Para George (2007), o crescimento econômico não necessariamente tem que contribuir para o desenvolvimento social. Ele pode ter efeitos negativos sobre a qualidade de vida, tendo em vista os resultados do rendimento social ou até mesmo um efeito negativo global. Por outro lado, quaisquer que sejam os efeitos que possam ter sobre a melhoria da qualidade de vida, o crescimento é necessário para manter a estabilidade econômica. 
Para Swanson e Pintér (2006), as estratégias de desenvolvimento sustentável são processos complexos e representam uma abordagem sistemática para transformar o seu conceito em prática. Eles afirmam que esses processos exigem esforço a longo prazo e por isso precisam ser abordados como processos de aprendizagem. Para os referidos autores, a avaliação das estratégias de desenvolvimento sustentável desempenha um papel fundamental nesse processo de aprendizagem.

A Estratégia Mundial de Conservação, de 1980, o relatório Brundtland, de 1987, a Conferência da Terra, realizada no Rio de Janeiro, de 1992, e a Conferência de Johanesburgo, de 2002, contêm informações do que foi dito em Estocolmo em 1972,i.e.,que o "homem tecnológico" está em um curso que poderá alterar perigosamente, e talvez irreversivelmente, os sistemas naturais do planeta, sobre os quais dependem sua sobrevivência biológica. A pobreza foi reduzida em alguns países, mas não em outros, as alterações climáticas induzidas pelo homem e a perda de biodiversidade continuam, apesar do alto índice de atenção internacional.

Embora de maneira transversal, o conceito de governança perpassa as preocupações dos tratados e conferências internacionais sobre desenvolvimento sustentável. Um exemplo de preocupação de tais eventos mundiais é a sugestão de precaução e cuidado, principalmente por parte dos gestores públicos, em relação a processos de desenvolvimento que comprometem a qualidade de vida humana em detrimento das questões tecnológicas e de crescimento econômico.

Para Kaufmann; Kraay; Mastruzzi (2006), Governança é um conceito plural e integrador, que difere do conceito de gestão. Traduz-se pela articulação de atores, empresários, terceiro setor, governos de diversos níveis e demais segmentos da sociedade, capazes de se fazer representar em projetos e planos que apontam para uma cidade utópica, com qualidade de vida e ampla sustentabilidade ou liderança compartilhada.

\section{Governança e indicadores de sustentabilidade}

O tema governança, bem como seus indicadores pelo mundo afora, é o resultado de um projeto de investigação sobre indicadores encomendado pelo Banco Mundial, no fim dos anos 1990. Os indicadores medem seis dimensões da governança: a representação e a prestação de contas, estabilidade política

REVISTA GRIFOS - N. 32/33 - 2012 
e ausência de violência, eficácia governamental e regulação da qualidade, da regra lei, e controle da corrupção (KAUFMANN; KRAAY; MASTRUZZI, 2006).

Para Kaufmann, Kraay, e Mastruzzi (2004), as dimensões de governança representam:

a) Representação pública e prestação de contas: à medida que um cidadão do país é capaz de participar na seleção dos seus governos, assim como a liberdade de expressão, liberdade de associação, e meios de comunicação livres;

b) Estabilidade política e ausência de violência: percepção de que a probabilidade do governo vir a ser desestabilizado ou derrubado por inconstitucionalidade ou meios violentos, incluindo a violência política e terrorismo;

c) Eficácia no governo: a qualidade dos serviços públicos, a qualidade do funcionalismo público e do seu grau de independência, livre de pressões políticas, qualidade da formulação e execução de políticas, e da credibilidade do Governo no cumprimento de tais políticas;

d) Regulamentação da qualidade: capacidade do governo de formular e programar sólidas políticas e regulamentos que permitam promover o desenvolvimento do setor privado;

e) Estado de direito: à medida que tenham confiança nos agentes e respeito às regras da sociedade, e, nomeadamente, à qualidade da execução contratual, à polícia, e aos tribunais, bem como à probabilidade de criminalidade e violência;

f) Controle da corrupção, na medida em que se exerce o poder público para ganho privado, incluindo tanto mesquinhas e grandes formas de corrupção, quanto "captura" do Estado por elites e os interesses privados.

Swanson e Pintér (2006) por outro lado, realizaram um estudo encomendado pela Organização de Cooperação e Desenvolvimento Econômico (OCDE), em cerca de vinte países, para identificar exemplos de estruturas e de boas práticas de governança, a fim de estudar a eficácia de estratégias de desenvolvimento sustentável. Seus estudos dão atenção especial 
à governança relacionada às seguintes estruturas: a natureza da estratégia de coordenação; colocação de responsabilidade global para estratégias nacionais de desenvolvimento sustentável; legislações subjacentes; integração com os processos de planejamento e orçamento; envolvimento dos interessados, e participação com ações locais de desenvolvimento sustentável.

A figura 01 a seguir mostra o resultado detectado na pesquisa de Swanson e Pintér (2006), na qual se estabeleceram seis elementos de governança e seus critérios de efetividade.

Figura 01: Elementos de governança e critérios de efetividade

\begin{tabular}{|c|c|}
\hline $\begin{array}{l}\text { Elementos de } \\
\text { Governança }\end{array}$ & Critérios de efetividade \\
\hline $\begin{array}{l}\text { 1. Natureza da } \\
\text { estratégia e da } \\
\text { coordenação do } \\
\text { governo }\end{array}$ & $\begin{array}{l}\text { Relevância e extensão: quanto mais departamentos } \\
\text { e níveis do governo para os quais as estratégias de } \\
\text { desenvolvimento sustentável são relevantes, melhor. Isso } \\
\text { demonstra que essas estratégias são detalhadas no que diz } \\
\text { respeito a questões econômicas, sociais e ambientais. } \\
\text { Participação do departamento: quanto mais os indivíduos } \\
\text { nos departamentos e nos outros níveis do governo estão } \\
\text { envolvidos nos processos estratégicos de desenvolvimento } \\
\text { sustentável, melhor. }\end{array}$ \\
\hline $\begin{array}{l}\text { 2. Colocação da } \\
\text { responsabilidade } \\
\text { total na Liderança }\end{array}$ & $\begin{array}{l}\text { Liderança Top-level (alto nível): quanto mais envolvido } \\
\text { o Primeiro Ministro ou o Presidente nos processos de } \\
\text { estratégias de desenvolvimento sustentável, melhor. }\end{array}$ \\
\hline $\begin{array}{l}\text { 3. Suporte legis- } \\
\text { lativo }\end{array}$ & $\begin{array}{l}\text { Envolvimento legislativo: quanto mais encaixado estiver } \\
\text { o processo de estratégias de desenvolvimento sustentável } \\
\text { na legislação, melhor. }\end{array}$ \\
\hline $\begin{array}{l}\text { 4. Participação } \\
\text { nos processos } \\
\text { orçamentários }\end{array}$ & $\begin{array}{l}\text { Integração: quanto maior a integração da visão e dos } \\
\text { objetivos de estratégias de desenvolvimento sustentável } \\
\text { para as plantas, além de orçamentos submetidos por } \\
\text { departamentos àqueles responsáveis pelo planejamento e } \\
\text { pelas finanças, melhor. }\end{array}$ \\
\hline $\begin{array}{l}\text { 5. Participação } \\
\text { dos interessados }\end{array}$ & $\begin{array}{l}\text { Formalidade: quanto mais formal a exigência para a participa- } \\
\text { ção da parte interessada no desenvolvimento e na execução de } \\
\text { estratégias de desenvolvimento sustentável, melhor. } \\
\text { Multi-parte interessada: quanto mais larga a perspectiva } \\
\text { alcançada com a participação da parte interessada, melhor. }\end{array}$ \\
\hline $\begin{array}{l}\text { 6. Participação } \\
\text { nos níveis locais }\end{array}$ & $\begin{array}{l}\text { Orientação: quanto mais esclarecedora a recomendação } \\
\text { nas estratégias de desenvolvimento sustentável no nível } \\
\text { de estado/províncias e da comunidade, melhor. } \\
\text { Sub-coordenação nacional: quanto mais coordenação } \\
\text { entre os objetivos de estratégias de desenvolvimento } \\
\text { sustentável e os objetivos do estado em níveis provinciais } \\
\text { e de comunidade, melhor. }\end{array}$ \\
\hline
\end{tabular}


O modelo teórico apresentado remete a elementos de governança voltados à indicação de práticas que pudessem conduzir as ações a fim de ampliar a possibilidade de eficiência em um processo de mudança das ações práticas e/ou estratégias com características sustentáveis. Também remete ao sentido de empoderamento das ações por diferentes atores sociais, no que diz respeito ao endógeno (de baixo para cima) e não objetivamente à estrutura e/ou hierarquia da organização quer seja ela pública ou privada.

A seguir, são apresentados de forma resumida, exemplos de boas práticas de sustentabilidade aplicadas nas 21 jurisdições levantadas por Swanson e Pintér (2006). Os países considerados no estudo de Swanson e Pintér representam uma mistura de dezesseis países da OCDE, sendo quatro países não membros da OCDE, e União Europeia. Foram incluídos na pesquisa: África do Sul, Alemanha, Bélgica, Brasil, Canadá, China, Coréia do Sul, Eslováquia, Filipinas, Finlândia, França, Irlanda, Itália, México, Noruega, Portugal, Reino Unido, República Checa, Suécia, Suíça e União Européia.

Figura 02: Estrutura de governança de alguns países e exemplos de boas práticas de sustentabilidade

\begin{tabular}{|c|c|c|}
\hline $\begin{array}{l}\text { Estrutura de } \\
\text { Governança }\end{array}$ & País & $\begin{array}{l}\text { Exemplos de boas práticas de sustentabili- } \\
\text { dade }\end{array}$ \\
\hline $\begin{array}{l}\text { 1. Natureza da } \\
\text { estratégia e da } \\
\text { coordenação do } \\
\text { governo }\end{array}$ & $\begin{array}{l}\text { Reino } \\
\text { Unido } \\
\text { Noruega }\end{array}$ & $\begin{array}{l}\text { - Estratégia de Desenvolvimento } \\
\text { Sustentável do Reino Unido 2005; } \\
\text { Estrutura Estratégica do Reino Unido } \\
\text { para o Desenvolvimento Sustentável; Ação } \\
\text { Comunitária 2020; } \\
\text { - Estratégia Nacional para o } \\
\text { Desenvolvimento Sustentável; Plano } \\
\text { Nacional de Ações para o Desenvolvimento } \\
\text { Sustentável; Declaração de Fredrikstad. }\end{array}$ \\
\hline $\begin{array}{l}\text { 2. Colocação } \\
\text { da responsabi- } \\
\text { lidade total na } \\
\text { Liderança }\end{array}$ & $\begin{array}{c}\begin{array}{c}\text { Alema- } \\
\text { nha }\end{array} \\
\text { Noruega } \\
\text { Suécia }\end{array}$ & $\begin{array}{l}\text { - Guia de competências do Chanceler; } \\
\text { - Escritório Oficial do Primeiro Ministro e } \\
\text { Comitê especial presidido pelo Ministro das } \\
\text { Finanças; } \\
\text { - Ministério do Desenvolvimento } \\
\text { Sustentável (fusão de Energia, Meio } \\
\text { Ambiente, e Departamento de Planejamento } \\
\text { e Suporte). }\end{array}$ \\
\hline $\begin{array}{l}\text { 3. Suporte } \\
\text { legislativo }\end{array}$ & $\begin{array}{l}\text { Canadá } \\
\text { Suíça }\end{array}$ & $\begin{array}{l}\text { - Estratégias departamentais de Auditoria } \\
\text { Geral de contas a cada três anos; } \\
\text { - Constituição Federal Suíça (1999). }\end{array}$ \\
\hline
\end{tabular}




\begin{tabular}{|c|c|c|}
\hline $\begin{array}{l}\text { Estrutura de } \\
\text { Governança }\end{array}$ & País & $\begin{array}{l}\text { Exemplos de boas práticas de sustentabili- } \\
\text { dade }\end{array}$ \\
\hline $\begin{array}{l}\text { 4. Participação } \\
\text { nos processos } \\
\text { orçamentários }\end{array}$ & Noruega & $\begin{array}{l}\text { - Plano de Ação Nacional adotado como } \\
\text { parte do Orçamento Nacional 2004. Essa } \\
\text { ação nacional encarrega-se da execução da } \\
\text { estratégia de Desenvolvimento Sustentável } \\
\text { com os processos regulares do planejamento } \\
\text { e do orçamento de autoridades setoriais } \\
\text { nacionais. }\end{array}$ \\
\hline $\begin{array}{l}\text { 5. Participação } \\
\text { dos interessa- } \\
\text { dos }\end{array}$ & $\begin{array}{l}\text { França } \\
\text { Reino } \\
\text { Unido } \\
\text { Finlândia } \\
\text { República } \\
\text { Checa }\end{array}$ & $\begin{array}{l}\text { - Conselho Nacional de Desenvolvimento } \\
\text { Sustentável (90 membros); } \\
\text { - Comissão de Desenvolvimento } \\
\text { Sustentável (ligações às regiões); } \\
\text { - Comissão Nacional Finlandesa de } \\
\text { Desenvolvimento Sustentável; } \\
\text { - Conselho Governamental para o } \\
\text { Desenvolvimento Sustentável. }\end{array}$ \\
\hline $\begin{array}{l}\text { 6. Participação } \\
\text { nos níveis } \\
\text { locais }\end{array}$ & $\begin{array}{l}\text { Suíça } \\
\text { França }\end{array}$ & $\begin{array}{l}\text { - Critérios de qualidade desenvolvidos, } \\
\text { "atores da autoridade pública a níveis } \\
\text { territoriais, regionais e municipais que } \\
\text { estão empreendendo um processo de } \\
\text { desenvolvimento sustentável novo ou que } \\
\text { desejam melhorar um processo existente } \\
\text { (Suíça, 2006)." } \\
\text { - } 119 \text { Agendas } 21 \text { Locais. Três níveis de } \\
\text { planos (distritais, inter-distritais e Agendas } \\
21 \text { locais). }\end{array}$ \\
\hline
\end{tabular}

Fonte: Adaptação de Darren Swanson e László Pintér (2006).

Os critérios introduzidos na Figura 1 fornecem a base para a identificação de exemplos de boas práticas entre os países estudados para cada um dos elementos governança apresentados na Figura 2, como exemplo de boas práticas adotadas por cada país na pesquisa de Swanson e Pintér (2006).

\section{Indicadores de sustentabilidade para o setor público}

Os indicadores de desenvolvimento sustentável devem ser desenvolvidos para proporcionar sólidas bases para a tomada de decisões em todos os níveis e para contribuir para uma autoregulamentação de sustentabilidade do meio ambiente e de sistemas de desenvolvimento integrado (Organização das Nações Unidas de 1992, p.284). 
O Instituto Internacional para Desenvolvimento Sustentável (IISD) abriga, desde 1995, o Compêndio de Iniciativas de Indicadores de Desenvolvimento Sustentável. É uma constatação da popularidade crescente de indicadores de sustentabilidade, úteis pelo vasto número de aplicações práticas que fornecem. É uma das mais extensas fontes de informação sobre indicadores e iniciativas de desenvolvimento sustentável em torno do mundo.

Este arcabouço de indicadores de desenvolvimento sustentável centra-se em três domínios: sustentabilidade-social, ambiental e econômica. A revisão da literatura disponível sobre os sistemas indicadores de sustentabilidade sugere que a seleção destes dependerá do que se está tentando medir.

Para Hardi e Zdan (1997 apud RUST, 2007), os indicadores não se traduzem como um fenômeno novo, embora tenham recebido cada vez mais atenção e uso. Em 1987, a Comissão Mundial para o Meio Ambiente e Desenvolvimento chamou de "[...] o desenvolvimento de novos caminhos para medir e avaliar o progresso através do desenvolvimento sustentável"(p. ). A popularidade dos indicadores deve-se ao fato de que: "[...] é necessário um rio de informações para entender o mundo, tomar decisões e planejar nossas ações" (MEADOWS, 1998, p.19).

A identificação e o acompanhamento dos indicadores consequentemente se tornam um instrumento de mudança e/ou de aprendizagem. Sistemas de Indicadores foram desenvolvidos por um grande número de organizações de todo o mundo, em diferentes escalas que vão desde às comunidades locais ou nacionais aos governos provinciais, tribos ou organizações internacionais para orientar políticas e decisões (ORGANIZAÇÃO DAS NAÇÕES UNIDAS DE 1992; BOSSEL, 1999).

Desempenhando um papel importante no ciclo político, os indicadores podem servir para um propósito útil, no discurso sobre desenvolvimento sustentável. Podem ajudar a assimilar e compreender melhor a opinião das partes interessadas, contribuir para o processo de governança, ajudar a orientar e moldar as decisões políticas.

Corroboram com esta assertiva Pintér, Swanson e Barr (2004). Para os citados autores, a avaliação e a comunicação de indicadores desempenham papéis importantes. A questão é complexa porque: as comunidades políticas são diversificadas; as políticas são diversificadas; os indicadores são diversificados; e os usos de indicadores são diversos. Além disso, indicadores são medidas 
quantitativas que expressam a situação e as tendências de fenômenos complexos com base em dados de controle e com a atenção nos interesses do público, que fornecem uma resposta clara à pergunta sobre as alterações ambientais e de sustentabilidade e ajudam a explicar como as decisões e os resultados estão ligados à decisão e possuir indicadores certos irá resultar em melhores decisões.

Indicadores não conduzem automaticamente e facilmente a alterações na política, na verdade, eles são muitas vezes utilizados com segundas intenções: na política são utilizados para apoiar uma determinada posição, simbolicamente podem ser desenvolvidos para dar ritualística adequada sobre as atitudes em relação à garantia de tomada de decisão, e taticamente atrasando ou um substituto para a ação (PINTÉR; SWANSON; BARR, 2004).

Hezri (2003 apud PINTÉR; SWANSON; BARR, 2004) afirma que, idealmente, os indicadores devem informar para a tomada de decisões nos seguintes aspectos: conceitual, uma vez que podem ser utilizados como um instrumento para ilustrar conceitos, ajudando a mudar o entendimento de uma questão; e instrumental, visto que podem revelar uma relação direta entre os indicadores e os resultados decisão. Podem, por exemplo, ser usados para medir o impacto de determinadas decisões e, quando utilizado para medir a eficácia, eles podem ser um instrumental na mudança de políticas.

Para compreender a utilização de indicadores no processo de tomada de decisão, deve-se primeiro olhar para o ciclo de tomada de decisões. A elaboração de políticas é um ciclo que envolve planejamento, implantação, avaliação, aprendizagem e adaptação. Indicadores desempenham um papel importante ao ajudar a delinear os objetivos políticos em termos específicos, ao permitir o acompanhamento dos progressos realizados e fornecer feedback (retorno) aos gestores e ao público sobre os resultados. Assumindo que uma simples ligação entre as políticas e os resultados poderia ser feita, indicadores podem desempenhar um papel fundamental de aprendizagem e de adaptação na política de maneira contínua, o que nem sempre acontece (PINTÉR; SWANSON; BARR, 2004).

O objetivo de indicadores de desenvolvimento sustentável, portanto, é o de ajudar e apoiar os gestores políticos e garantir que eles tomem decisões melhores informadas. Muitas organizações internacionais, países e regiões têm desenvolvido indicadores, mas poucos têm a sua utilização real controlada. $\mathrm{O}$ governo finlandês, por exemplo, desenvolveu um conjunto de indicadores de desenvolvimento sustentável que foi tornado público na primavera

REVISTA GRIFOS - N. 32/33 - 2012 
de 2000. O processo de desenvolvimento destes indicadores envolveu um grande número de cientistas, funcionários públicos e Organizações Não Governamentais.

Um estudo de acompanhamento feito por Rosenström (2002) junto a gestores políticos finlandeses, para examinar o potencial de indicadores de desenvolvimento mostra que, embora os indicadores sejam considerados como um conceito promissor, a sua utilização ainda é marginal e sua promoção é necessária. Apenas um grupo restrito de gestores públicos tinha utilizado o conjunto de indicadores estabelecidos antes do estudo de acompanhamento. A maioria dos entrevistados, até então, havia considerado o melhor uso dos indicadores como material para discursos e apresentações, e consideram sua utilização direta no processo de tomada de decisões menos significativa.

Pintér, Swanson e Barr (2004) mostram na Figura 3 um ciclo político ilustrado pelo qual passa uma política tendo como base intenções de atingir indicadores (econômicos, ambientais e sociais). Neste ciclo a aplicação da política está voltada para o público-alvo que a partir de suas decisões e ações em torno da intencionalidade política elaborarão respostas sobre sua eficácia e análise de desempenho, no sentido de reforçar a intenção original proposta. Essa conceituação foi desenvolvida como parte do Programa das Nações Unidas para o Meio Ambiente (The United Nations Environment Programme - UNEP, 1992).

Figura 03: O ciclo político ilustrado

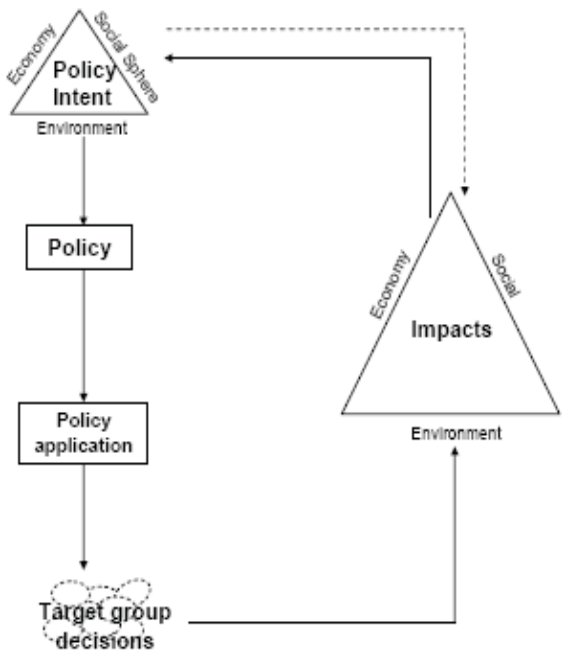

Fonte: Pintér, Swanson e Barr, (2004, p. 10) 
Uma intenção ou meta política adotada por um governo envolve pelo menos três dimensões relacionadas (econômica, ambiental e social). A política é aplicada ao público-alvo. $\mathrm{O}$ seu caráter e força são influenciados pelo grau de entendimento e o vigor com que é aplicada. Uma vez adotada, a política vai afetar o público-alvo, que a partir de suas decisões e ações gerarão impactos nas três esferas supracitadas. A análise da eficácia da política vai determinar em que medida os resultados desejados foram alcançados ou não, tornando-se necessário conduzir a política a revisões para melhorar o seu desempenho. Nesse sentido, os indicadores são utilizados para identificar e medir os efeitos políticos e a eficácia política (PINTÉR; SWANSON; BARR, 2004). Pintér, Swanson e Barr (2004) ilustram essa sequência com um exemplo:

Objetivos e metas: um governo nacional institui uma política de apoio à mudança climática esforços internacionais para travar as influências humanas sobre o aquecimento global. Ela estabelece metas de redução de gases de efeito estufa.

Estratégias e instrumentos: inicia incentivos financeiros, tais como energia, impostos; instrumentos jurídicos, tais como limites para as emissões; e de outras estratégias, tais como o apoio orçamental para o transporte público, que se destina a ajudar a alcançar os objetivos e as metas.

Execução Política: governos regionais e locais, através do acompanhamento da execução das políticas e fazer respeitar os limites das emissões na indústria, por exemplo, e de melhoria e aumento ônibus, metrô e trem de serviços, e de ciclovias.

Avaliação de Impacto: Os indicadores são utilizados para medir a eficácia da política de mudança. Por exemplo, iria ajudar a avaliar os indicadores de desempenho da política através da comparação de dados sobre as emissões de gases com efeito de antes e depois da mudança política e na comparação entre a taxa de progresso para o objetivo pretendido. Os indicadores devem servir para informar a tomada de decisões em um ciclo de aprendizagem adaptativas.

Exemplos práticos de estratégias de desenvolvimento sustentável e estruturas de governança são identificados, fornecendo critérios inerentemente subjetivos, dado o amplo leque de abordagens para a governança em países diferentes, e devido à natureza dinâmica e política de gestão do setor público. No entanto, a atenção para esses critérios proporciona um meio útil para a autoavaliação e melhoria contínua em estratégias nacionais 
de desenvolvimento sustentável e governança (SWANSON; PINTÉR, 2006).

Cardinal e Adin (2005 apud RUST, 2007) desenvolveram um painel de sustentabilidade, caracterizado por indicadores de qualidade de vida urbana indígena na Região da Grande Vancouver. O seu relatório é um recurso valioso, uma vez que não existem muitos trabalhos que versam sobre a população aborígine urbana no Canadá e na criação de sistemas de indicadores. Os autores adaptaram sua metodologia a partir do sistema de objetivos da UNESCO, incorporando ensinamentos e crenças tradicionais aborígenes. Ao utilizar este método combinado, os autores afirmam que é possível englobar os aspectos e relacionamentos holísticos críticos para superar a tradicional fragmentação das estruturas convencionais de indicadores, conforme a figura 04.

Figura 04: Painel de sustentabilidade - Vida urbana aborígine

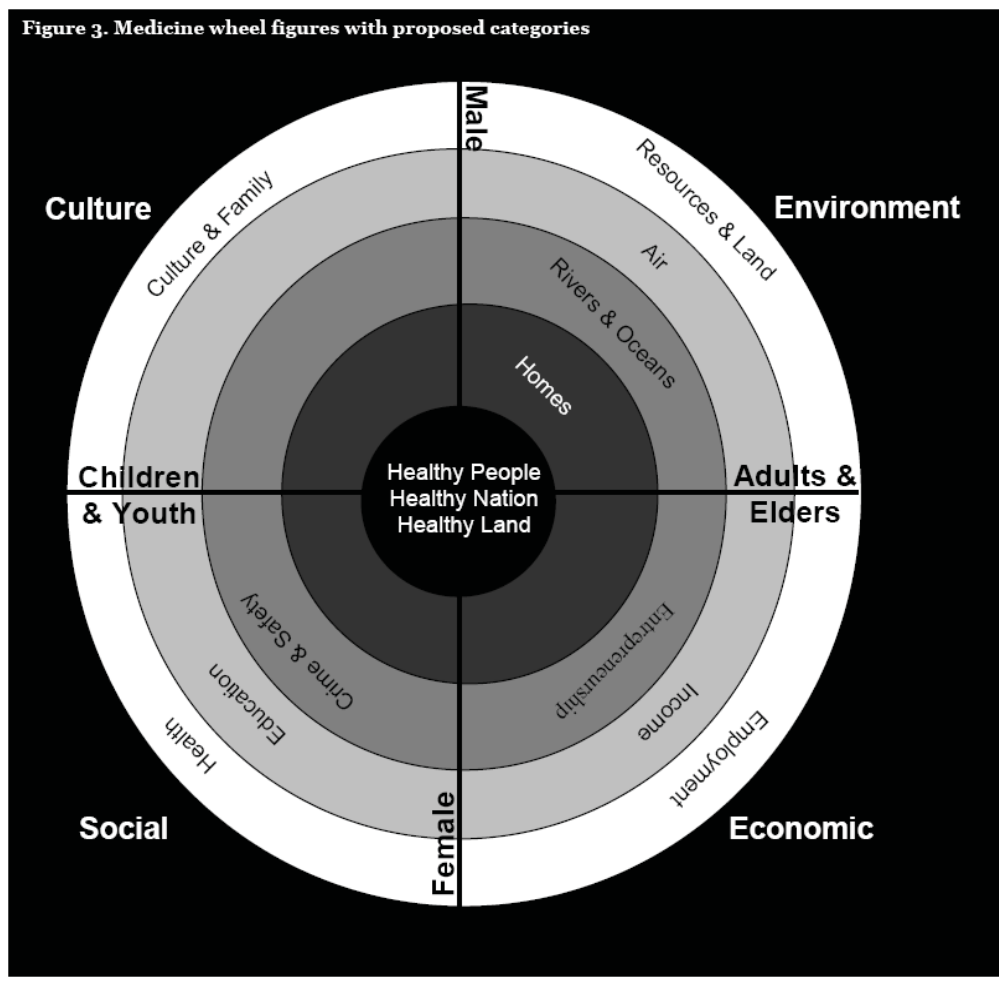

Fonte: Cardinal e Adin (2005 apud RUST, 2007, p. 15)

A seleção do painel de sustentabilidade é essencial para o sucesso dos projetos e utilidade dos indicadores. Existem 
muitos tipos de painéis de sustentabilidade. A roda da medicina, por exemplo, é empregada para abordar os indicadores mais tipicamente encontrados em obras relacionadas com a saúde. Ainda que estes painéis forneçam um foco mais específico para uma determinada área de preocupação, a literatura disponível sobre eles foi reexaminada para aprofundar o contexto aborígine no que diz respeito aos sistemas de indicadores (RUST, 2007).

Com o objetivo de desenvolvimento de indicadores comunitários de saúde, Lickers (2002 apud RUST, 2007), em um projeto plurianual em comunidades na reserva de Ontário, elaborou um modelo baseado na roda da medicina que foi utilizado para integrar e avaliar as quatro ligações expressas pela roda e desenvolver indicadores de saúde da comunidade que foram mensuráveis e quantificáveis (INSTITUTO DO MEIO AMBIENTE, 2002 apud RUST, 2007).

O referido modelo mostra a interconexão da comunidade em questões de saúde holística e traça soluções que poderiam ser mobilizadas para sanar problemas crescentes. A fim de manter o equilíbrio entre os indicadores da saúde humana, a comunidade deve manter uma abordagem equilibrada para a vida, como representado na figura 05 .

Figura 05: Painel de sustentabilidade - Eagle Eye View (Visão Olho de Águia)

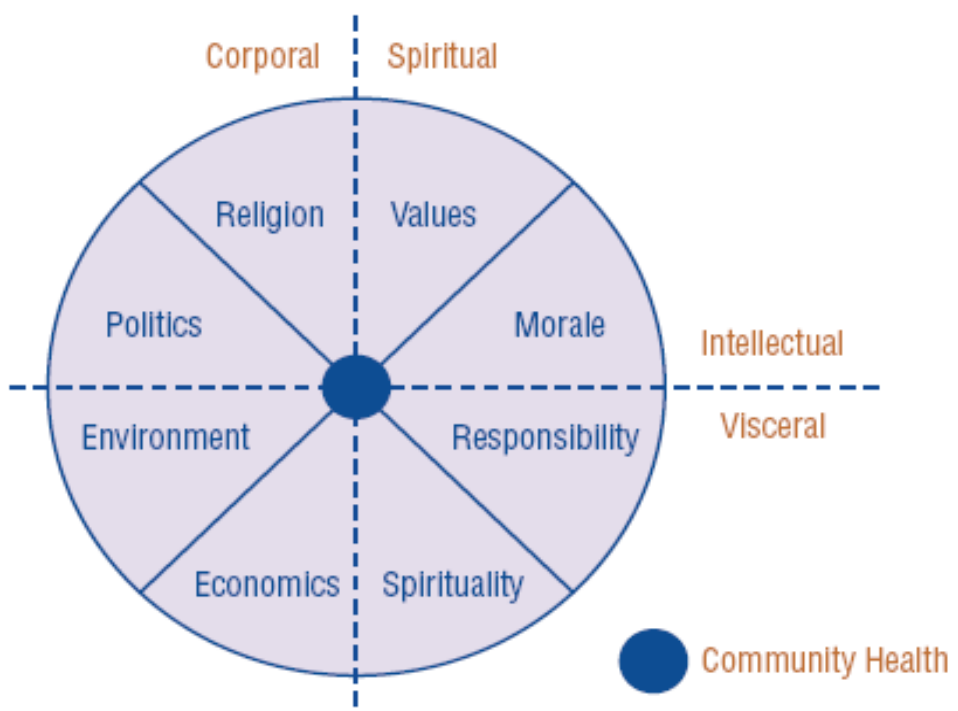

Fonte: Instituto do Meio Ambiente (2002 apud RUST, 2007, p. 17)

REVISTA GRIFOS - N. 32/33 - 2012 
Dado o número de painéis disponíveis é recomendado

que se considere uma pré-visão orientada para a seleção e o enquadramento de indicadores e interpretação da comunicação dos resultados desde a concepção do projeto. Os Princípios Bellagio (1996) foram criados para servir esse efeito e proporcionar um elo entre a teoria e a prática, afirmam Hardi e Zdan (1997 apud RUST, 2007). Recomenda-se que os painéis devam ser construídos mediante os seguintes 10 princípios essenciais: Orientadores de visão e metas; Perspectivas holísticas; Elementos essenciais; Âmbito adequado; Foco prático; A abertura; Uma comunicação eficaz; Ampla participação; Avaliação em curso, e Capacidade institucional.

Cardinal e Adin (2005 apud RUST, 2007) tomaram por base esses princípios ao insistir na necessidade de uma abordagem holística e estrutura interativa em consonância com o contexto da sua investigação. Significativa importância é colocada na construção de uma série de feedbacks no âmbito do design, categoria seleção e identificação indicadora para garantir que o sistema seja representativo de as preocupações e os valores do povo. A seleção do painel, portanto, necessita ponderar e integrar os pontos de vista e opiniões, às vezes divergentes, do público-alvo.

\section{Questões gerais sobre sustentabilidade no Brasil}

O contexto brasileiro, embora diferenciado, merece alguns destaques. $\mathrm{O}$ primeiro deles refere-se à participação brasileira na Conferência de Johanesburgo, um encontro que decorreu na África do Sul entre 26 de agosto e 4 de setembro de 2002. Durante dez dias, líderes mundiais reuniram-se para debater o que fazer para tratar do ambiente terrestre. Porém, para o Brasil, uma das maiores desilusões da Conferência de Johanesburgo foi a derrota das propostas da União Européia e do Brasil para o mundo da primeira meta global de energia renovável.

Em matéria de energias renováveis, a tentativa por parte da União Européia para introduzir a mundo da primeira meta global de energia renovável de trabalhar em estreita colaboração com o Governo dos Estados Unidos e delegados da indústria, foi derrotada por alguns países da OPEP (Organização dos Países Produtores de Petróleo). As propostas européias foram modestas (15 por cento da sua meta global teria significado um aumento de apenas 1 (um) ponto percentual sobre o valor atual de todas 
as tecnologias de energias renováveis) comparativamente às propostas do Brasil, com o apoio da Argentina e um número de outros países em desenvolvimento (DORAN, 2002). Ao contrário da União Européia, afirma Doran (2002), o Brasil só queria incluir novas energias renováveis, por exemplo: solar, eólica, rural e tecnologias, tais como sistemas de grandes centrais hidroelétricas.

$\mathrm{Na}$ Conferência de Joanesburgo, ministros exprimiram o seu apoio para o Protocolo de Quioto. A Conferência marcou a retirada dos Estados Unidos do referido Protocolo. O Brasil, assim como a China, Índia e Tailândia anunciaram a sua ratificação. $O$ outro destaque reside no âmbito dos produtos químicos, o Brasil sediou o III Fórum Internacional sobre Segurança Química, encontro realizado na Bahia, em outubro 2000, onde os participantes identificaram as tarefas que tenham sido concluídas ou em que os progressos estavam ainda em curso para concretizar a intenção do Capítulo 19 da Agenda 21 (DORAN, 2002).

Uma estratégia de prioridades para abordar questões futuras até ao IV Fórum foram acordadas, estabelecidos na Declaração da Bahia sobre Segurança Química e das prioridades de ação para além de 2000. O Plano de Aplicação referia-se em: renovar o compromisso, como avançado na Agenda 21, a boa gestão dos produtos químicos durante o seu ciclo de vida e de resíduos perigosos para a sustentabilidade, o desenvolvimento e a proteção da saúde humana e do ambiente, entre outras.

Essas estratégias eram destinadas a conseguir que, até 2020, produtos químicos fossem utilizados e produzidos com os mínimos efeitos adversos significativos na saúde humana e no ambiente, utilizando transparência com base em fundamentos científicos e procedimentos de avaliação de riscos à base da ciência e procedimentos de gestão de riscos, tendo em conta a precaução, tal como estabelecido no princípio 15 da Declaração do Rio sobre Meio Ambiente e Desenvolvimento (DORAN, 2002).

Doran (2002) comenta ainda que a outra proposta consistisse em apoiar os países em desenvolvimento a reforçar sua capacidade de boa gestão dos produtos químicos e de resíduos perigosos, fornecendo assistência técnica e financeira, continuar a desenvolver uma abordagem estratégica à gestão internacional dos produtos químicos com base na Declaração da Bahia, prioridades de ação para além do Fórum Intergovernamental de Segurança Química (IFCS) e instar que o Programa das Nações Unidas para o Meio 
Ambiente (PNUA), e outras organizações internacionais e atores que lidam com produtos químicos, cooperassem estreitamente nesta matéria.

\section{Considerações finais}

A maioria das aplicações dos sistemas de desenvolvimento sustentável dos países deveria estar ligada ao planejamento dos governos e sistemas de realização de orçamento. A ausência desse tipo de ligação é uma deficiência, pois esta poderia ser uma boa prática para a eficácia da administração de sistemas de desenvolvimento sustentável. Porém, vê-se uma oportunidade enorme emergir. Ao mesmo tempo em que os governantes desenvolvem seus sistemas associados da governança $\mathrm{e}$ patrocinados por departamentos ambientais, os governos através dos seus departamentos igualmente fazem avanços importantes na sua responsabilidade, através de processos departamentais anuais, ou do planejamento e elaboração de relatórios. Em ambos os casos, gestores políticos e governo, têm uma finalidade comum: o progresso real para avanços na qualidade de vida de seus cidadãos.

Para que os sistemas da responsabilidade do governo tornem-se mais estratégicos e orientados para resultados, um conceito sofisticado do desenvolvimento futuro é exigido: o conceito do desenvolvimento sustentável integrando perspectivas econômicas, sociais e ambientais torna-se mais estratégico. A sinergia entre estes dois componentes da administração é urgente e necessária para se obter o progresso real e oportuno para a ação estratégica e coordenada do desenvolvimento sustentável. Essa sinergia pode ser facilitada centrando-se mais esforço sobre a análise dos componentes de boas práticas no planejamento, da responsabilidade e nos relatórios de sistemas. Se a governança global integrada controlasse o ambiente global eficazmente, removeria as ameaças econômicas levantadas ao longo da História.

Enquanto o desenvolvimento sustentável se move a mais de duas décadas para ajustar-se às suas agendas, a demanda para a prática da política de sustentação pode crescer a título exponencial. Espera-se que com a passagem do tempo, uma apreciação do significado da Agenda 21 e os acordos do UNCED cresçam e o discurso do desenvolvimento sustentável seja encaixado em ações políticas voltadas para a democracia, justiça econômica, direitos humanos e participação. Seremos impressos 
pelo uso do desenvolvimento sustentável relacionados muito mais com a qualidade da prática. Nesse processo, reivindicações normativas associadas ao desenvolvimento sustentável migrarão para instituições globais exigindo normas democráticas de responsabilidade e transparência ao setor público. A tarefa de identificar indicadores da estrutura social e econômica deve agora ser incentivada e torna-se um grande desafio para cada disciplina das ciências sociais. As diferenças entre grandes países apresentam uma oportunidade para o desenvolvimento conjunto dos sistemas econômicos e das estruturas novas da administração no mundo de forma sustentável, ecológica, social e tecnologicamente integrada.

\section{Referências}

RUST, Christa. Building Knowledge, Measuring Well-being Developing Sustainability Indicators for Winnipeg's First Nations Community. Pre-publication Version, October 2007.

DORAN, Peter. World Summit on Sustainable Development (Johannesburg): an assessment for IISD. For the International Institute for Sustainable Development Briefing Paper October 3, 2002.

GEORGE, Clive. Sustainable Development and Global Governance. The Journal of Environment \& Development. Volume 16 Number 1 University of Manchester, Sage Publications: March 2007, p. 102-125.

KAUFMANN, Daniel; KRAAY, Aart; MASTRUZZI, Massimo. Governance Matters V: aggregate and individual governance indicators for 1996-2005. The World Bank, 2006.

MEADOWS, Donella. Indicators and information systems for sustainable development. The Sustainability Institute, 1998.

MINEUR, Eva. Towards Sustainable Development: Indicators as a tool of local governance. Department of Political Science. Umeå University, Sweden Research report. Printed by: Print \& Media, 2007.

OSBORNE, David; GAEBLER, Ted. Reinventando o governo. 8 ed. Brasília: Editora MH Comunicação, 1992.

PINTÉR, László; SWANSON, Darren; BARR, Jane E. Use of Indicators in Policy Analysis: Annotated training module prepared for the World Bank Institute, 2004. 
ROSENSTRÖM, Ulla. Indicators and Methodology: the potential

for the use of sustainable development indicators in policy-making in Finland, 2002.

SWANSON, Darren; PINTÉR, László. Governance Structures for National Sustainable Development Strategies: Study of Good Practice Examples and International Institute for Sustainable Development (IISD). Prepared for: The Organization for Economic Co-operation and Development (OECD): October $1^{\text {st }}, 2006$.

UNITED NATIONS CONFERENCE ON ENVIRONMENT AND DEVELOPMENT (UNCED). Rio de Janeiro, 1992.

WORLD BANK. World development report 2000/2001. Washington: World Bank, 2002. Disponível em <http://worldbank.org>. Acesso em: 10 jun. 2011.

\title{
SUSTAINABLE DEVELOPMENT: GOVERNANCE AND INDICATORS FOR THE PUBLIC SECTOR
}

\begin{abstract}
This paper presents reflections on sustainable development, governance and sustainability indicators, especially in regard to what is being developed by the governmental public management. It presents a survey on the following themes: Sustainable development, governance, sustainability indicators for the public sector and general questions on sustainability in Brazil. This is a review of literature of qualitative approach. The results demonstrate the use of performance indicators in political analyses in the sustainable development context to support public managers and to ensure they make more informed decisions. Many international organizations, countries and regions have introduced the use of indicators, but few have controlled their use.
\end{abstract}

Keywords: Sustainable Development. Governance Indicators for Sustainability. Sustainability in Brazil. 